\title{
Approaching Reactive Arthritis Associated With Poor Prognostic Factors: A Case Report and Literature Review
}

\author{
Swetha Ann Alexander ${ }^{1}$, Eunjung Kim ${ }^{2}$, Ranadeep Mandhadi ${ }^{2}$ \\ 1. Internal Medicine, University of Connecticut, Farmington, USA 2. Rheumatology, University of Connecticut, \\ Farmington, USA
}

Corresponding author: Swetha Ann Alexander, salexander@uchc.edu

\begin{abstract}
The aim of this paper is to review and discuss the background, common manifestations, differential diagnosis, and current treatment practices of reactive arthritis. The focus will be on the choice of therapy in patients with poor prognostic factors. A PubMed search was performed in March 2020 on reactive arthritis and revealed 137 articles. Fourteen case reports and four large-scale studies that are pertinent for discussion in terms of treatment of reactive arthritis over the past five years are reported along with poor prognostic markers. The first choice of therapy regardless of the number of poor prognostic markers is non-steroidal anti-inflammatory drugs (NSAIDs). The second choice of therapy appeared to be glucocorticoids in the oral as well as intra-articular forms. No correlation was detected between the need for systemic steroids and the number of poor prognostic factors present. The third choice of therapy appears to be disease-modifying antirheumatic drugs (DMARDs) (such as sulfasalazine) and their increasing use can be demonstrated over time. Novel therapies such as adalimumab have also been shown to be used and this shows a strong correlation with an increased number of poor prognostic factors. Reporting of these case reports and review of literature contribute to knowing more about reactive arthritis and help keep us up to date with newer therapies available when patients do not respond to conventional therapy. It was notable that the increased number of poor prognostic factors and non-responders have shown increased use of tumor necrosis factor inhibitors (TNFI) such as adalimumab.
\end{abstract}

Review began 02/13/2021 Review ended 02/24/2021 Published 02/25/2021

\section{Copyright 2021}

Alexander et al. This is an open access article distributed under the terms of the Creative Commons Attribution License CC-BY 4.0., which permits unrestricted use, distribution, and reproduction in any medium, provided the original author and source are credited.
Categories: Internal Medicine, Rheumatology

Keywords: reactive arthritis, nsaid, dmard, biologic therapies, poor prognostic markers, glucocorticoids, adalimumab, keratoderma blennorrhagicum, dactylitis

\section{Introduction}

Reactive arthritis (ReA) is a disease of a rare incidence and therefore internists and rheumatologists alike have limited encounters with diagnosing and treating the disease. We present a diagnostically and therapeutically challenging case of ReA. The patient had presented with multiple poor prognostic factors that posed unique challenges in treating this rare and intriguing disease. A literature review was performed to identify the best treatment modalities known to work in people with different prognostic factors. Given the rarity of ReA, we aim to review and discuss the background, common manifestations, differential diagnosis, and treatment of the disorder.

\section{Case Presentation}

A 36-year-old African American man with a past medical history of herpes simplex virus (HSV) infection presented to the emergency department with a chief complaint of right knee pain and swelling of a couple of weeks. The symptoms began shortly after the patient returned from his trip to Minnesota where he was diagnosed with gonococcal urethritis by urine polymerase chain reaction (PCR) at a local emergency department. He had initially presented with a thick white urethral discharge and had been treated with one dose of cefixime $400 \mathrm{mg}$ and doxycycline $100 \mathrm{mg}$ twice a day for seven days. The patient returned to Connecticut and presumably finished his antibiotics treatment.

Over the next two weeks, the patient developed right knee pain and swelling and sought care in an outside emergency room. He was noted to have bilateral conjunctival injection in addition to right knee synovitis. He was given ibuprofen as well as erythromycin ophthalmic ointment. The patient returned the following day to the same emergency room due to minimal relief of his knee pain and this time was given prednisone taper for five days starting with $50 \mathrm{mg}$ daily. Six days later, he presented to our emergency department with ongoing right knee pain.

Upon presentation, the patient also endorsed complaints of right ankle pain and swelling as well as left lateral hip pain. He had also complained of open sores on his penis, which per patient felt very similar to his prior HSV outbreaks. On further questioning, he noted feeling febrile but denied fatigue, weight loss, eye pain or redness, vision changes, rhinitis, ear discharge, chest pain, shortness of breath, abdominal 


\section{Cureus}

discomfort, nausea, vomiting, diarrhea, dysuria or urethral discharge. Patient admitted to smoking about two to three cigarettes a day and drinking alcohol occasionally but denied use of illicit drugs. He has had multiple sexual partners over the past six months and did not use protection.

On physical examination, he was febrile $\left(102.9^{\circ} \mathrm{F}\right)$ and tachycardic (129 beats per minute). He was found to have bilateral conjunctival erythema with normal pupil size and light reactivity. Two non-tender, subcentimeter, and elliptical-shaped dry ulcers with erythematous base were found on the hard palate of his mouth. There were a few mildly tender, non-purulent and sub-centimeter ulcers on his penis. There was no inguinal lymphadenopathy. His right knee was extremely warm, tender, and swollen. The range of motion was also limited due to pain. He had similar warmth, tenderness and swelling over the right ankle, and tenderness was noted over the left trochanteric bursa. Sausage-shaped swelling, consistent with dactylitis, of his right second toe was noted (Figure 1). Bilateral plantar surfaces were covered with hyperkeratotic hyperpigmented plaques consistent with keratoderma blennorrhagicum (Figure 2).

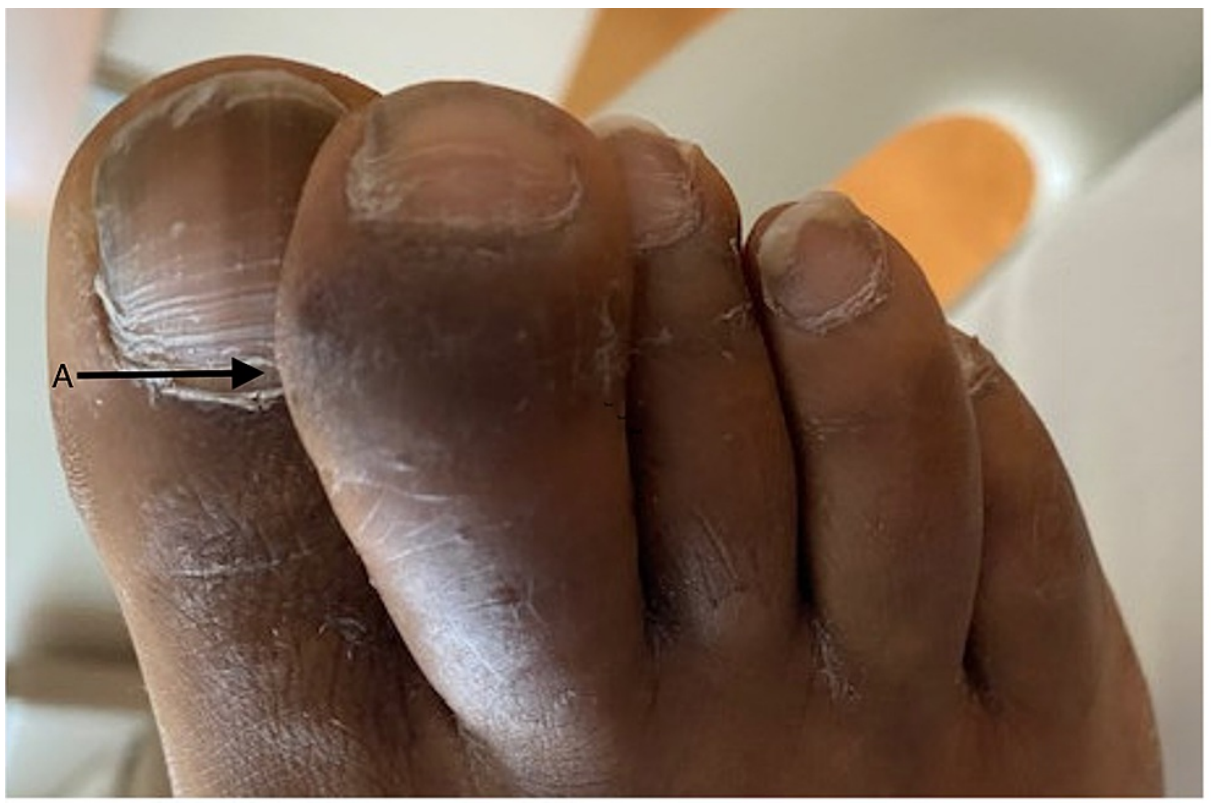

FIGURE 1: Dactylitis of the second toe

As shown by black arrow $(\mathrm{A})$

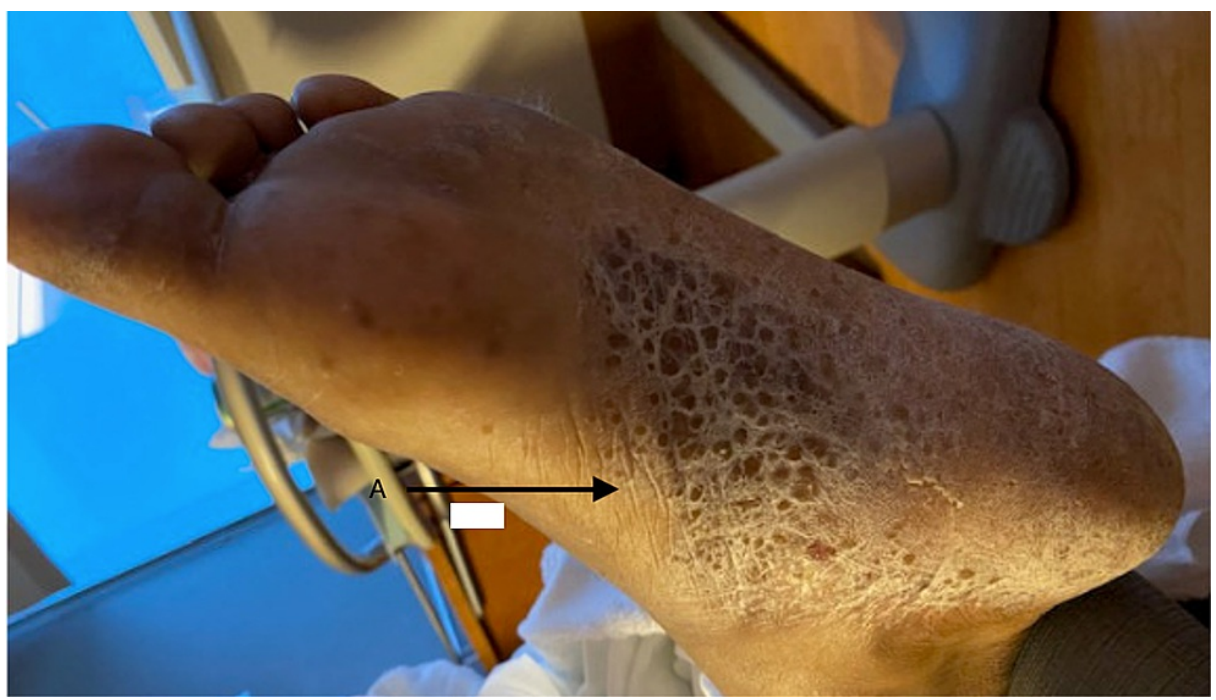

FIGURE 2: Keratoderma Blennorrhagicum

As shown by black arrow (A) 
Lab work showed leukocytosis (white cell count of $24.0 / \mathrm{\mu L}$ ) and significantly elevated inflammatory markers (erythrocyte sedimentation rate [ESR] of $>130 \mathrm{~mm} / \mathrm{hr}$; C-reactive protein [CRP] of $262 \mathrm{mg} / \mathrm{L}$ ). Right knee arthrocentesis revealed a turbid aspirate with 23,778 white blood cell count with $88 \%$ neutrophils. Gram stain was negative.

The patient was empirically started on ceftriaxone for disseminated gonococcal infection and azithromycin to cover for chlamydia. He was also given valacyclovir for herpetic ulcers on his penis. Despite treatment with antibiotics, he had persistent fevers and synovitis of the right knee and ankle. Repeat gonorrhea and chlamydia PCR returned negative. Human immunodeficiency virus (HIV), hepatitis B virus (HBV), hepatitis $\mathrm{C}$ virus (HCV), tuberculosis, syphilis, Lyme, Anaplasma, and Babesia also returned negative. Synovial cultures from initial as well as repeat arthrocentesis remained negative. Magnetic resonance imaging (MRI) of the right knee and ankle showed joint effusion but no other underlying abnormality was found. Human leukocyte antigen B27 (HLA-B27) was positive.

Given patient's lower extremity predominant oligoarthritis, conjunctivitis, recent history of gonococcal urethritis, dactylitis, a classic rash of keratoderma blennorrhagicum and HLA-B27 positivity, a diagnosis of reactive arthritis was made. He was initially treated with ketorolac without much improvement in his joint symptoms. He was subsequently placed on two alternative non-steroidal anti-inflammatory drugs (NSAIDs) one after the other (indomethacin and diclofenac). A complete resolution of left trochanteric bursa pain was achieved with the NSAIDs, however debilitating pain in the right knee and ankle persisted. Finally, oral prednisone $40 \mathrm{mg}$ daily was initiated with resolution of his fever and improvement of right knee and ankle synovitis. He was discharged home on prednisone with a plan for rheumatology outpatient follow-up. His total hospital stay was 12 days.

Patient was re-admitted to the hospital 10 days later due to persistent synovitis involving the right knee and ankle and a new-onset left knee synovitis. On further probing patient stated that he was non-adherent with taking prednisone at home. Repeat arthrocentesis again revealed aseptic inflammatory aspirate. He was started on intravenous methylprednisolone $40 \mathrm{mg}$ twice a day along with sulfasalazine $500 \mathrm{mg}$ twice a day. The patient's joint symptoms improved markedly over the next two days and he was discharged on oral prednisone. Unfortunately, he was lost to follow up upon discharge.

\section{Discussion}

Multiple attempts to establish a guideline in order to define ReA after collaborating clinical and lab data have been made, however, none have been universally accepted or been validated. Current preliminary classification criteria for ReA, which has been widely used, is composed of two major and two minor criteria. A diagnosis of 'definitive ReA' is made if both major criteria and one relevant minor criterion are met. A diagnosis of 'probable ReA' is made when both major criteria without relevant minor criteria or one major criterion with one or more minor criteria are met [1]. The major and minor criteria of ReA are demonstrated in Table 1.

\section{Major Criteria}

Arthritis, with two of the following three findings: Asymmetric Monoarthritis or oligoarthritis Predominantly affecting lower limbs Preceding symptomatic infection 3 days to 6 weeks before the onset of arthritis: Enteritis (defined as diarrhea for at least 1 day) or urethritis (dysuria or discharge for at least 1 day)

\section{Minor Criteria}

Evidence of triggering infection: NAAT test from morning urine or urethral swab for Chlamydia Positive stool culture for enteric pathogens associated with reactive arthritis Evidence of persistent synovial infection: Positive immunohistology or PCR assay for Chlamydia

\section{TABLE 1: Reactive Arthritis Diagnostic Criteria}

NAAT- Nucleic acid amplification test; PCR- Polymerase chain reaction

Clinical presentation of ReA varies widely ranging from the absence of symptoms to multi-systemic involvement. Usually, the course of disease starts with an infectious etiology leading to the development of arthritis (95\%) after about one to four weeks [2]. Summarized in Table 2 are the potential clinical manifestations of ReA. Other causes of acute arthritis must be ruled out prior to the diagnosis of ReA (Table 3). 


\section{Cureus}

Organ Involvement Typical Clinical Presentations

Musculoskeletal Asymmetric lower limb oligoarthritis Dactylitis Sacroiliitis Enthesitis

Skin and Nail Circinate balanitis Keratoderma Blennorrhagica Psoriatic onychodystrophy Painless ulcers in the mouth

Eye $\quad$ Conjunctivitis Corneal ulceration Episcleritis Keratitis Uveitis

Genitourinary Cervicitis/Salpingitis/Vulvovaginitis in women Urethritis and Prostatitis in men

Gastrointestinal Acute diarrhea resembling inflammatory bowel disease

Heart (Rare) Ascending aortitis Conduction abnormalities

TABLE 2: Clinical Features of Reactive Arthritis Represented by Organ System

Diagnosis

Septic Arthritis

Gout

Pseudogout

Rheumatoid Arthritis Flare

Psoriatic Arthritis

Lyme Arthritis

STI related arthritis

Lupus Arthritis

Inflammatory bowel

disease-associated arthritis

Sarcoid arthropathy
Characteristic Features

Mono or oligoarticular involvement with joint effusion showing elevated WBC counts (e.g. $>50,000$ cells/microL) and positive synovial fluid cultures for causative organism.

Monosodium urate crystals present on synovial fluid analysis with elevated WBC counts

Calcium pyrophosphate crystals present on synovial fluid analysis with elevated WBC counts

Symmetric polyarticular involvement with positive serology (RF/anti-CCP antibodies), elevated acute phase reactants (ESR/CRP)

Oligo- or polyarthritis with onycholysis and psoriatic skin lesion

Mono- or oligoarthritis with positive Lyme serology

Based on the serology of the virus

Migratory, polyarticular and symmetric involvement with systemic features of SLE

Peripheral arthritis with spondylitis and history of inflammatory bowel disease

Oligo or polyarthritis associated with hilar adenopathy and erythema nodosum

\section{TABLE 3: Differential Diagnosis for Reactive Arthritis}

WBC- white blood cell; RF-rheumatoid Factor; CCP-cyclic citrullinated peptide; ESR-erythrocyte sedimentation rate; CRP-C-reactive protein; STI- sexually transmitted infection; SLE- systemic lupus erythematosus

Clinical course of reactive arthritis is variable. It can spontaneously resolve or progress to chronic arthritis which is defined as persistence of symptoms for greater than six months. More than half of the cases that have a chronic course are usually triggered by genitourinary organisms as compared to enteric organisms. This can be secondary to increased rates of reinfection with genitourinary organisms such as Chlamydia trachomatis and Neisseria gonorrhea.

Certain factors on presentation are indicative of poor prognosis as they point towards a more severe spectrum of the disease. These factors include male sex, age of disease onset less than 16 years, HLA-B27 positivity, heel and foot involvement, arthritis of the hip, lumbar spine stiffness, dactylitis, oligoarthritis, ESR greater than $30 \mathrm{~mm}$ in the first hour, and poor response to NSAIDs.

A multifaceted approach to treatment is required based on the natural course of the disease and the clinical course of the patient. The goals of treatment are threefold: 1) reduce pain and inflammation, 2) minimize disability, and 3) prevent relapse or progression to chronic disease. Initially, the treatment of an underlying genitourinary infection with antibiotics is essential but the same approach does not apply for enteric infections with rare exceptions (e.g. Clostridium difficile).

Considering the long hospital course of our patient and his multiple poor prognostic factors, we sought out to review what the recent treatment practice patterns of ReA were. We especially wanted to examine the 


\section{Cureus}

impact of poor prognostic factors on physicians' treatment regimens and the need for escalation of therapy to disease-modifying anti-rheumatic drugs (DMARDs) or biologics in such cases. Additionally, we hoped to investigate if there was any correlation between early initiation of prednisone (prior to use of NSAIDs) and decreased requirement of DMARDs or biologics use.

A review of the literature was performed through a Medical Subject Headings (MeSH) search of PubMed for all articles on 'Reactive Arthritis' published within the last five years. It revealed 137 articles as of March 2020 from which case reports and large-scale data reported in English were included. We analyzed 14 case reports and four large-scale studies that are pertinent for our discussion. The case reports and the large studies are displayed in Table 4 [3-16] and Table 5 [17-20], respectively. We risk-stratified the case reports by poor prognostic factors and analyzed the treatment options in the order they were used in each case study. 


\section{Cureus}

\begin{tabular}{|c|c|c|c|c|c|c|}
\hline Number & Author & Year & $\begin{array}{l}\text { Country } \\
\text { Of } \\
\text { Study }\end{array}$ & Diagnosis & $\begin{array}{l}\text { Choices of therapy in the } \\
\text { order of use }\end{array}$ & Poor prognostic factors \\
\hline 1 & $\begin{array}{l}\text { Sumlyoshı } \\
\text { et al. [15] }\end{array}$ & 2019 & Japan & ReA and gout & $\begin{array}{l}\text { Loxoprofen, } \\
\text { Salazosulfapyridine, } \\
\text { Adalimumab }\end{array}$ & $\begin{array}{l}\text { Male sex, Foot involvement, Elevated } \\
\text { ESR, HLA-B } 27 \text { positivity, Poor } \\
\text { response to NSAIDs }\end{array}$ \\
\hline 2 & $\begin{array}{l}\text { Hoversten } \\
\text { et al. [9] }\end{array}$ & 2018 & USA & $\operatorname{ReA}$ & $\begin{array}{l}\text { NSAID, Prednisone, } \\
\text { Sulfasalazine, } \\
\text { Adalimumab }\end{array}$ & $\begin{array}{l}\text { Male sex, Oligoarthritis, Elevated } \\
\text { ESR, HLA-B27 positivity, Poor } \\
\text { response to NSAIDs }\end{array}$ \\
\hline 3 & et al. [4] & 2017 & France & $\begin{array}{l}\text { ReA secondary to } \\
\text { Salmonella enteritidis }\end{array}$ & $\begin{array}{l}\text { Ketoprofen, Sulfasalazine, } \\
\text { Etanercept }\end{array}$ & $\begin{array}{l}\text { Oligoarthritis, Dactylitis, Elevated } \\
\text { ESR, HLA-B27 positivity, Poor } \\
\text { response to NSAIDs }\end{array}$ \\
\hline 4 & $\begin{array}{l}\text { Michiels } \\
\text { et al. [12] }\end{array}$ & 2019 & Belgium & $\operatorname{ReA}$ & $\begin{array}{l}\text { Local glucocorticoid, } \\
\text { Etoricoxib, Sulfasalazine }\end{array}$ & $\begin{array}{l}\text { Male Sex, Oligoarthritis, Dactylitis, } \\
\text { HLA-B27 positivity }\end{array}$ \\
\hline 5 & $\begin{array}{l}\text { Erre et al. } \\
{[6]}\end{array}$ & 2019 & Italy & $\begin{array}{l}\text { Hafnia alvei induced } \\
\text { ReA }\end{array}$ & NSAID, Ciprofloxacin & $\begin{array}{l}\text { Male sex, Oligoarthritis, Elevated } \\
\text { ESR, Poor response to NSAIDs }\end{array}$ \\
\hline 6 & $\begin{array}{l}\text { Hsing et } \\
\text { al. [10] }\end{array}$ & 2017 & Australia & $\operatorname{ReA}$ & $\begin{array}{l}\text { Naproxen, Prednisolone, } \\
\text { Sulfasalazine }\end{array}$ & $\begin{array}{l}\text { Male sex, Elevated ESR, HLA-B } 27 \\
\text { positivity, Poor response to NSAIDs }\end{array}$ \\
\hline 7 & $\begin{array}{l}\text { Nishizaki } \\
\text { et al. [14] }\end{array}$ & 2016 & Japan & ReA & $\begin{array}{l}\text { NSAID, Prednisolone } \\
\text { taper, Methotrexate }\end{array}$ & $\begin{array}{l}\text { Male sex, Oligoarthritis, HLA-B } 27 \\
\text { positivity, Poor response to NSAIDs }\end{array}$ \\
\hline 8 & $\begin{array}{l}\text { Kawahara } \\
\text { et al. [11] }\end{array}$ & 2018 & Japan & $\begin{array}{l}\text { ReA secondary to } \\
\text { Neisseria meningitidis }\end{array}$ & $\begin{array}{l}\text { Antibiotics, Prednisolone, } \\
\text { Methotrexate }\end{array}$ & $\begin{array}{l}\text { Male sex, Oligoarthritis, HLA-B27 } \\
\text { positivity }\end{array}$ \\
\hline 9 & $\begin{array}{l}\text { Eguchi et } \\
\text { al. [5] }\end{array}$ & 2019 & Japan & $\begin{array}{l}\text { Haemophilus } \\
\text { parainfluenzae induced } \\
\text { ReA }\end{array}$ & Ampicillin & Oligoarthritis, Elevated ESR \\
\hline 10 & $\begin{array}{l}\text { Yoshımura } \\
\text { et al. [16] }\end{array}$ & 2018 & Japan & $\begin{array}{l}\text { Intravesical bacillus } \\
\text { Calmette-Guerin (BCG) } \\
\text { induced ReA }\end{array}$ & $\begin{array}{l}\text { NSAID therapy, } \\
\text { Methotrexate, } \\
\text { Salazosulfapyridine, } \\
\text { Prednisolone }\end{array}$ & Male sex, Oligoarthritis \\
\hline 11 & $\begin{array}{l}\text { Coelho et } \\
\text { al. [3] }\end{array}$ & 2017 & Portugal & $\operatorname{ReA}$ & $\begin{array}{l}\text { Antibiotics, NSAID, } \\
\text { Sulfasalazine }\end{array}$ & Oligoarthritis, HLA-B27 positivity \\
\hline 12 & $\begin{array}{l}\mathrm{Ng} \text { et al. } \\
{[13]}\end{array}$ & 2015 & Italy & $\begin{array}{l}\text { ReA after intravesical } \\
\text { BCG instillations }\end{array}$ & NSAID & Male sex, Oligoarthritis \\
\hline 13 & $\begin{array}{l}\text { Gałąska et } \\
\text { al. [8] }\end{array}$ & 2019 & Poland & $\begin{array}{l}\text { Yersinia induced ReA } \\
\text { and Aortitis }\end{array}$ & $\begin{array}{l}\text { Naproxen, Oral } \\
\text { corticosteroids, } \\
\text { Cyclophosphamide }\end{array}$ & Oligoarthritis \\
\hline 14 & $\begin{array}{l}\text { Foschi et } \\
\text { al. [7] }\end{array}$ & 2016 & Italy & $\begin{array}{l}\text { ReA secondary to LGV } \\
\text { infection }\end{array}$ & Doxycycline, Ketoprofen & Dactylitis \\
\hline
\end{tabular}

TABLE 4: Case Reports of Reactive Arthritis with Choices of Treatment and Poor Prognostic factors

ReA- reactive arthritis; HLA-B27- human leucocyte antigen- B27; ESR- erythrocyte sedimentation rate; NSAIDs- nonsteroidal anti-inflammatory agents; BCG-bacillus Calmette-Guerin; LGV- Iymphoma granuloma venerum 


\section{Cureus}

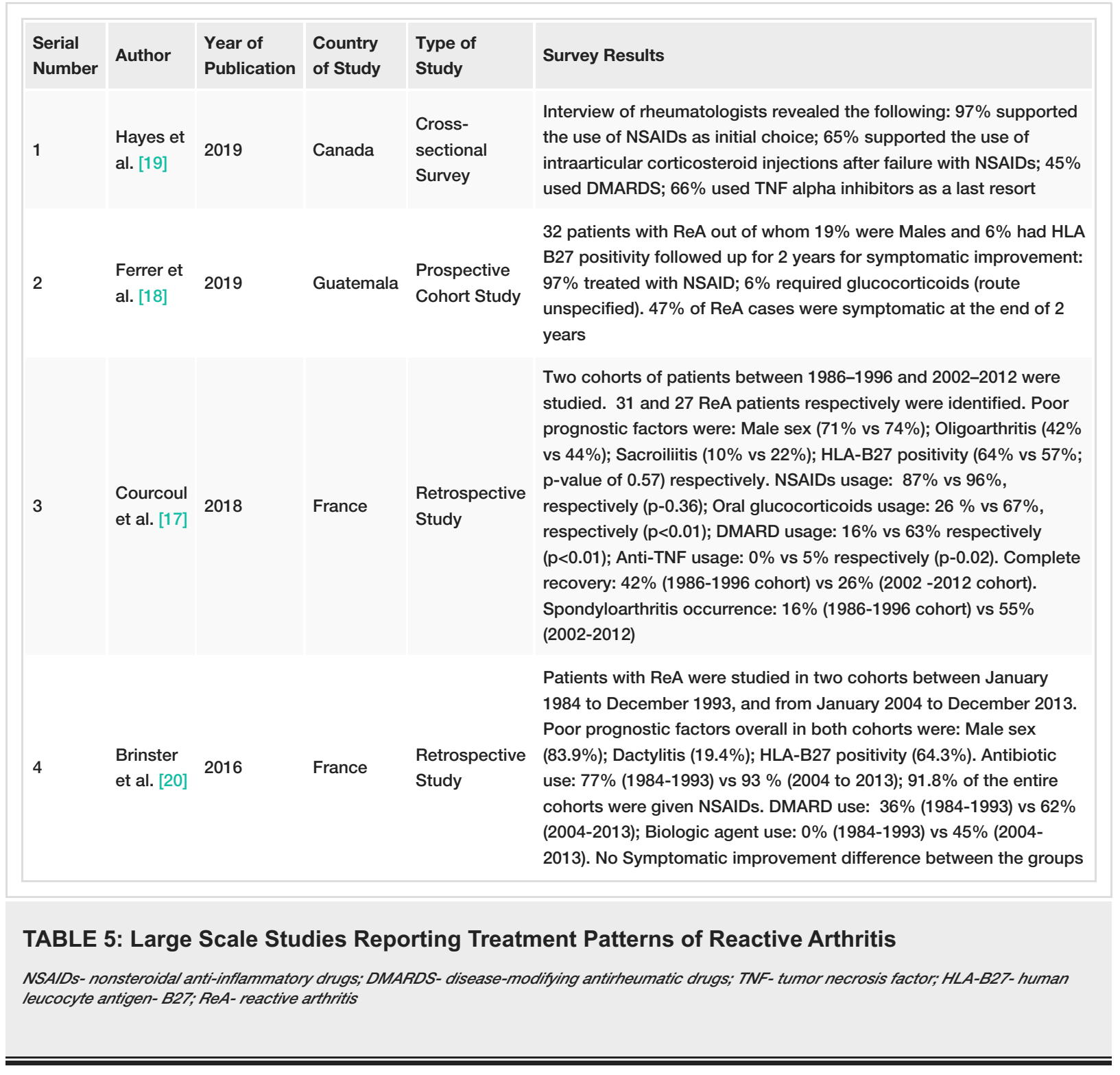

Among the 14 case reports mentioned above, 11 case reports documented the use of NSAIDs as the first choice of therapy. NSAID therapy was a second choice seen in case number 4 (Table 4), after non-relief with intra-articular glucocorticoid use [12]. This supports that NSAIDs appears to be the first choice of therapy.

Five case reports documented the use of oral steroids as the second choice of therapy after non-relief with NSAIDs $[8-11,14,16]$. Case number 8 (Table 4 ) initiated oral steroids as a first line therapy, followed by DMARD therapy for additional symptom control [11]. Case number 10 chose oral steroid after trial of NSAID and DMARD therapy for symptomatic management [16]. Out of these five cases which required oral steroids after failure with NSAIDs, one case presented with five poor prognostic factors, two cases with four poor prognostic factors, one with three poor prognostic factors and one with two poor prognostic factors [8$10,14]$. They uniformly required the use of DMARDs. This depicts that higher number of prognostic factors lead to escalation of therapy from NSAID to glucocorticoid use.

Interestingly, case number 1 and case number 10 (Table 4) initiated DMARDs and TNF inhibitors (TNFI) even before the use of oral steroids $[15,16]$. Case numbers 1 and 2 (Table 4 ) have demonstrated the use of adalimumab $[9,15]$. It is notable to mention that five or greater prognostic factors were identified in both cases in which adalimumab was used. The use of TNFI is increasing over the years and symptomatic improvement with its use is seen in about $20 \%$ of cases $[17,20]$.

Large-scale studies are reported in Table 5. A cross-sectional survey in Canada (study 1, Table 5) showed that intra-articular glucocorticoid treatment has been used widely among $65 \%$ of the rheumatologists [19]. A prospective cohort study from Guatemala (study 2, Table 5) showed that $6 \%$ of their cohort required glucocorticoids treatment after non-relief with NSAIDs therapy alone and symptomatic improvement was seen in 53\% of the patients by the end of treatment with NSAID and glucocorticoid [18]. The route of glucocorticoids was not specified in this study. Table 5 includes two retrospective studies (studies 3 and 4) 
which compare the trend of treatment choices in the different time periods [17, 20]. A trend favoring the prevalent usage of DMARDs and biologics is seen after the year 2000.

Over the years, therapy for recalcitrant ReA has expanded which may reflect the general advancement of rheumatologic armamentaria. However, it appears NSAIDs are still used most commonly as first-line therapy in ReA and increased use of DMARDs or biologic does not always lead to resolution of symptoms. Initiation of early systemic steroid therapy does not seem to lessen the requirement of DMARDs when associated with poor prognostic factors. Even as little as two poor prognostic factors were associated with the use of DMARDs. Unfortunately, the timing of each treatment regimen in respect to symptom onset was not clearly denoted in the case reports and therefore, the effect of early treatment with systemic glucocorticoids on the need for subsequent escalation of treatment is unclear.

There are a few limitations in our literature search, as follows: First, only English language written articles were included so underreporting of ReA cases was inevitable. Secondly, no strict inclusion or exclusion criteria for the mentioned articles were in place. Articles that were included were those in which patients were diagnosed with ReA and treated for it. The aim was to review the treatment utilized and outcomes observed in ReA patients over the past five years. Third, they only include retrospective findings from the cases and large-scale studies and cannot fully assess for superiority or inferiority of each treatment regimen compared to each other and come with inherent limitations associated with retrospective studies.

The major strengths of this study are that it provides a single source to review many of the recently published case reports and large-scale studies focusing on the treatment choices and their relation to poor prognostic factors and symptomatic relief. It also discusses the treatment trends over time while reinforcing that NSAIDs are still the first line of therapy.

\section{Conclusions}

$\mathrm{ReA}$ is a rare form of arthritis and awareness of this condition is crucial for accurate diagnosis and initiation of appropriate therapy in a timely manner. We presented a case of ReA with multiple poor prognostic factors and reviewed various aspects of ReA including clinical manifestations and appropriate management strategies. Given the rarity of ReA, there is a lack of randomized controlled studies on treatment options. NSAIDs still continue to be the first treatment choice. Poor prognostic factors usually lead to escalation of therapy including treatment with the biologics. Initiation of systemic steroids did not necessarily prevent the need to escalate therapy to DMARDs or biologics, especially when associated with poor prognostic factors. There is a need to establish universally acceptable guidelines for identifying ReA so that prospective studies can be done to ascertain the best treatment strategy.

\section{Additional Information \\ Disclosures}

Human subjects: Consent was obtained or waived by all participants in this study. Conflicts of interest: In compliance with the ICMJE uniform disclosure form, all authors declare the following: Payment/services info: All authors have declared that no financial support was received from any organization for the submitted work. Financial relationships: All authors have declared that they have no financial relationships at present or within the previous three years with any organizations that might have an interest in the submitted work. Other relationships: All authors have declared that there are no other relationships or activities that could appear to have influenced the submitted work.

\section{References}

1. Selmi C, Gershwin ME: Diagnosis and classification of reactive arthritis . Autoimmun Rev. 2014, 13:546-549. 10.1016/j.autrev.2014.01.005

2. Hamdulay S, Glynne S, Keat A: When is arthritis reactive?. Postgrad Med J. 2006, 82:446-453. 10.1136/pgmj.2005.044057

3. Coelho I, Costa S, Mendes SS, Gomes GC: Keratoderma blennorrhagica. BMJ Case Rep. 2017, 2017:2017222475. 10.1136/bcr-2017-222475

4. Courcoul A, Muis PO, Tebib JG, Coury F: Early treatment of reactive arthritis with etanercept and 2 years follow-up. Joint Bone Spine. 2017, 84:367. 10.1016/j.jbspin.2016.05.002

5. Eguchi T, Horino T, Amano E, Ichii O, Terada Y: Reactive arthritis caused by haemophilus parainfluenzae in a diabetic patient. Am J Med. 2019, 132:519-520. 10.1016/j.amjmed.2018.11.007

6. Erre GL, Colombo E, Bibbò S, Dore MP: Reactive arthritis secondary to Hafnia alvei enterocolitis . BMJ Case Rep. 2019, 12:228513. 10.1136/bcr-2018-228513

7. Foschi C, Banzola N, Gaspari V, D’Antuono A, Cevenini R, Marangoni A: A case of reactive arthritis associated with lymphogranuloma venereum infection in a woman. Sex Transm Dis. 2016, 43:584-586. 10.1097/OLQ.0000000000000482

8. Gałąska R, Masiak A, Kulawiak-Gałąska D, Czuszyńska Z, Dorniak K, Fijałkowski M: Reactive arthritisassociated aortitis followed by Yersinia enterocolitica infection: multimodal imaging. Cardiol J. 2019, 26:298-299. 10.5603/CJ.2019.0060

9. Hoversten P, Beachey J, Pham M, Bhagra A: A rare cause of oligoarthritis with septic presentation . BMJ Case Rep. 2018, 2018:2017-223941. 10.1136/bcr-2017-223941 
10. Hsing YE, Walker J: Bilateral interstitial keratitis with anterior stromal infiltrates associated with reactive arthritis. BMJ Case Rep. 2017, 2017:2016-218419. 10.1136/bcr-2016-218419

11. Kawahara K, Mukai T, Miyaji Y, Morita Y: Chronic reactive arthritis associated with prostatitis caused by Neisseria meningitidis. BMJ Case Rep. 2018, 2018:2017-223537. 10.1136/bcr-2017-223537

12. Michiels S, Kerre S: Palate erosions in reactive arthritis . Arthritis Rheumatol. 2019, 71:2089-2089. 10.1002/art.41061

13. Ng KL, Chua CB: Reiter's syndrome postintravesical Bacillus Calmette-Guérin instillations. Asian J Surg. 2017, 40:163-165. 10.1016/j.asjsur.2014.01.016

14. Nishizaki Y, Yamagami S, Inoue H, Uehara Y, Kobayashi S, Daida H: Reactive arthritis caused by urinary tract infection. Intern Med. 2016, 55:1195-1198. 10.2169/internalmedicine.55.6112

15. Sumiyoshi R, Koga T, Tsuji S, et al.: Chlamydia-induced reactive arthritis diagnosed during gout flares: a case report and cumulative effect of inflammatory cytokines on chronic arthritis. Medicine. 2019, 98:e17233. 10.1097/MD.0000000000017233

16. Yoshimura H, Okano T, Inui K, Nakamura H: Ultrasonographic findings in a patient with reactive arthritis induced by intravesical BCG therapy for bladder cancer. J Med Ultrason. 2019, 46:163-165. 10.1007/s10396018-0889-7

17. Courcoul A, Brinster A, Decullier E, et al.: A bicentre retrospective study of features and outcomes of patients with reactive arthritis. Joint Bone Spine. 2018, 85:201-205. 10.1016/j.jbspin.2017.01.013

18. Ferrer HRG, Azan A, Iraheta I, et al.: Potential risk factors for reactive arthritis and persistence of symptoms at 2 years: a case-control study with longitudinal follow-up. Clin Rheumatol. 2018, 37:415-422. 10.1007/s10067-017-3911-3

19. Hayes KM, Hayes RJ, Turk MA, Pope JE: Evolving patterns of reactive arthritis . Clin Rheumatol. 2019, 38:2083-2088. 10.1007/s10067-019-04522-4

20. Brinster A, Guillot X, Prati C, Wendling D: Evolution over thirty years of the profile of inpatients with reactive arthritis in a tertiary rheumatology unit. Reumatol Clin. 2016, 14:36-39.

10.1016/j.reuma.2016.08.001 